\title{
Nitrogen Rich Heterocycles as a Privileged Fragment in Lead
}

\section{Discovery}

\author{
Hamid Irannejad* \\ Department of Medicinal chemistry, Mazandaran University of Medical Sciences, \\ Sari, Iran
}

*Corresponding author: Hamid Irannejad (Pharm.D, Ph.D), Department of Medicinal chemistry, Faculty of Pharmacy, Mazandaran University of Medical Sciences, Sari, Iran, Tel: 0098 9124572673; Email: irannejadhamid@gmail.com

\section{Mini Review \\ Volume 2 Issue 3}

Received Date: October 26, 2018

Published Date: November 14, 2018

DOI: $10.23880 /$ macij-16000125

\begin{abstract}
Nitrogen rich heterocycles such as pyrazole, imidazole, triazoles, tetrazole, triazines and their fused systems including imidazotriazines and triazolotriazines have been attracted medicinal chemists because of their prominent biological activities. Due to the presence of nitrogens as an electronegative atom, these heterocycles are capable of constituting various strong bonds. This capability has provoked the scientists to incorporate these fascinating fragments into their designed drug like molecules. This review attempts to summarize various pharmacological activities of nitrogen rich heterocyclic systems.
\end{abstract}

Keywords: Nitrogen rich heterocycles; Imidazole; Triazole; Triazine; Imidazotriazine; Triazolotriazine

Abbreviations: mTOR: mammalian Target of Rapamycin, PAD: Protein Arginine Deiminase, FAK: Focal Adhesion Kinase, IGF-1R: Insulin-like Growth Factor Receptor-1, IR: Insulin Receptor.

\section{Introduction}

Heterocyclic core systems are fascinating scaffolds for drug discovery and development process because of their potential to constitute various and essential bonds within the active site of their targets [1]. Among heteroatoms, nitrogen is of greater importance due to its high degree of electronegativity whereas can easily form polar bonds like dipole-dipole, $\pi$-dipole, $\pi$-charge transfer in $\pi-\pi$ stacking, ionic-dipole and hydrogen bonds. As we know, hydrogen bonding is of particular importance in biological environments and in this sense; nitrogen atoms can play roles as both hydrogen bond acceptor and donor (in the form of $\mathrm{NH}$ ) which makes this atom as a key element in lead discovery.

Nitrogen rich heterocycles are considered as pyrazole, imidazole, 1,2,3- and 1,2,4-triazole, tetrazole, 1,3,5- and 1,2,4-triazine and their fused systems named pyrazolotriazine, imidazotriazine and triazolotriazine (Figure 1). These heterocycles are widely used and incorporated into the structure of numerous synthetic drugs and pharmacologically active agents. Some of their pharmacological activity pertaining to these heterocycles are antifungals, antimicrobials, anticancer, anticonvulsants, anti-inflammatory and antihypertensive agents. In the following, we briefly describe some examples of recently introduced and discovered drug candidates containing nitrogen rich heterocycles. 
<smiles>c1cc[nH]c1</smiles>

Pyrazole<smiles>c1c[nH]cn1</smiles>

Imidazole

$$
\stackrel{\mathrm{N}}{\mathrm{N}} \stackrel{\mathrm{N}}{\mathrm{N}}\rangle
$$

1,2,3-triazole<smiles>c1ncncn1</smiles><smiles>c1cnncn1</smiles>

1,3,5-triazine

1,2,4-triazine<smiles>c1ncn2cncc2n1</smiles>

imidazo[1,5a] $[1,3,5]$ triazine<smiles>c1cnn2cnnc2n1</smiles>

$[1,2,4]$ triazolo[ $[4,3-b]$ $[1,2,4]$ triazine<smiles>c1cnn2cncc2n1</smiles>

imidazo[1,5-b] $[1,2,4]$ triazine

$$
\text { N N }
$$

Tetrazole

Figure 1: Different 5- and 6-membered and fused systems of nitrogen rich heterocycles.

\section{Bioactivities of Nitrogen Rich Heterocycles}

In a recent study by Abdellatif, et al. pyrazole core which was inspired by selective cyclooxygenase-2(COX-2) inhibitor celecoxib was used for the synthesis of new drug candidates as anti-inflammatory and anti-diabetic agents
(Figure 2). Their anti-inflammatory activity was acting through cyclooxygenase-2 inhibition whereas their antidiabetic effect was through inhibition of $\alpha$ - and $\beta$ glucosidase and PPAR- $\gamma$ activation. In fact, the reason behind the incorporation of pyrazole ring in the structure of designed compounds is to keep the Y-shape of coxibs like celecoxib [2].<smiles>[R]c1ccc(-c2nn(-c3ccc(S(C)(=O)=O)cc3)cc2/C=C2/SC(=O)NC2=O)cc1</smiles>

PPAR agonist and selective COX-2 inhibitor<smiles>Cc1ccc(-c2cc(C(F)(F)F)nn2-c2ccc(S(C)(=O)=O)cc2)cc1</smiles>

Celecoxib (a selective COX-2 inhibitor)

Figure 2: Pyrazole containing drugs with anti-inflammatory and selective COX-2 inhibition activity.

Recently, Taban, et al. reported a series of biaryl pyrazole imidazole and triazole as small molecules inhibitors of CYP121A1 with antimycobacterial activity
(Figure 3). Some of the derivatives with short -CH2linker between pyrazole core and imidazole/triazoles ring showed prominent antimycobacterial activity with low 
MIC values in the range of $6.25-25 \mu \mathrm{g} / \mathrm{ml}$. As we know, imidazole and triazole nitrogen atoms are suitable electron donors for forming a coordination bond with heme iron in the active site of CYP121A1 [3].

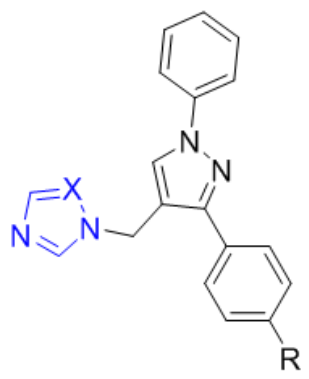

$\mathrm{X}=\mathrm{CH}, \mathrm{N}$

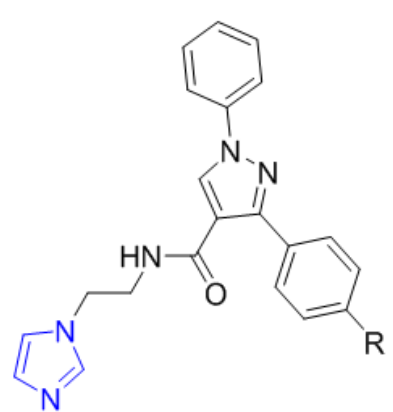

$\mathrm{R}$

\section{CYP121A1 inhibitor}

Figure 3: Imidazole/triazole containing drugs with CYP121A1 inhibition potential and anti mycobacterium activity.

A series of diphenyl conjugated imidazole derivatives were designed and synthesized as glutaminyl cyclase inhibitors (Figure 4). This enzyme is a key target in Alzheimer's initiation by generating neurotoxic pyroglutamate modified $\beta$-amyloid peptides. Synthesized compounds showed potent inhibitory activity against human glutaminyl cyclase along with high blood-brainbarrier permeability and could substantially reduce the level of amyloid plagues in the brain. The nitrogen atom of imidazole ring binds to the catalytic zinc ion at the pocket of glutaminyl cyclase to inhibit the enzyme [4].

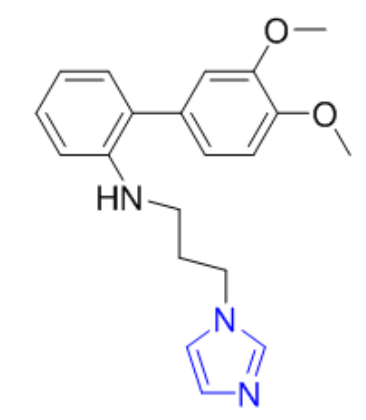

\section{Glutaminyl cyclase inhibitor}

Figure 4: Imidazole containing drug with glutaminyl cyclase activity useful in Alzheimer's disease.
A novel series of triazole containing mammalian target of rapamycin (mTOR) kinase inhibitors were synthesized and their potency, selectivity and pharmacokinetics were evaluated (Figure 5). SAR studies suggested that 4,6- or 1,7-disubstituted-3,4-dihydropyrazino[2,3-b]pyrazine$2(1 \mathrm{H})$-ones substituted by a terminal triazole showed improved pharmacokinetic and were highly potent and selective mTOR inhibitors. In this study, the best compound CC-115 was considered as a lead for further clinical development. Molecular docking of these compounds inside the active site of mTOR displayed that the triazole moiety extends deeply into the catalytic site and forms multiple hydrogen bonding interactions with Asp2195, Lys2187 and Ile2356 [5].<smiles>O=C1CN(CCC2CCOCC2)c2nc(-c3ccc(-c4nc[nH]n4)cc3)cnc2N1</smiles>

\section{mTOR kinase inhibitor}

Figure 5: Triazole containing drug with mTOR inhibition and anticancer activity.

Nowadays, Antifungal drugs are under great investigations due to the emerge of resistant fungi to the current antibiotics. Presence of an imidazole or triazoles ring is necessary in keeping anti fungus activity. Imidazole or triazole nitrogen atom constitutes a coordination bond with heme iron existed in the active site of lanosterol $14 \alpha-$ demethylase to block its catalytic activity. In this context, some fluconazole analogs containing triazole modified scaffolds were synthesized and their antifungal activity were evaluated (Figure 6). Among compounds tested, two of them showed very potent activity with MIC values ranging $\leq 0.01-0.5 \mu \mathrm{g} / \mathrm{ml}$ against Candida species even more effective than fluconazole $[6,7]$. 
<smiles>OC(Cn1cncn1)(Cn1cncn1)c1ccc(F)cc1F</smiles>

Fluconazole<smiles>[R][X]c1ccc(-c2nnc(SCC(O)(Cn3cncn3)c3ccc([X])cc3[X])[nH]2)cc1</smiles>

Fungal lanosterol 14-alpha-demethylase inhibitor

Figure 6: Triazole containing drugs with antifungal activity.<smiles>[R]#CC=CC(=O)NC(CCCNC(=N)CCl)c1nn[nH]n1</smiles>

\section{PAD inhibitor}

Figure 7: Tetrazole containing drug with PAD inhibition potential useful in autoimmune diseases.

Subramanian et al. reported tetrazole analogs of an amidine derivative in order to find potent, selective and orally bioavailable protein arginine deiminase (PAD) inhibitors (Figure 7). This enzyme catalyzes the hydrolysis of arginine residues to citrulline and plays role in autoimmune diseases like rheumatoid arthritis, multiple sclerosis, lupus, ulcerative colitis and in some types of cancer. In this sense, a bioisosteric replacement by tetrazole ring as a suitable mimic of amide bond gave prominent drug like compounds with better bioavailability [8].

In a study conducted at 2012, a series of 5,6-diaryl1,2,4-triazines were synthesized as Adenosine A2A antagonists (Figure 8). These compounds showed potent, selective and orally efficient drug candidates for treatment of Parkinson's disease [9].

Correspondingly, some 5,6-diaryl-1,2,4-triazine derivatives were reported to be selective cyclooxygenase2 inhibitors with high anti-inflammatory activity [10]. On the other hand, various 1,2,4-triazines were reported to have potent neuroprotective activity against $\mathrm{H} 2 \mathrm{O} 2$ and $\beta$ amyloid induced neurotoxicity in PC12 and SHSY5Y cell lines [11]. Similarly, the same 1,2,4-triazine compounds were shown to have high genoprotective activity against endosulfan mediated toxicity in lymphocytes [12].<smiles>[R]c1ccc(-c2nc(SC)nnc2-c2ccc(S(C)(=O)=O)cc2)cc1</smiles>

Selective COX-2 inhibitor<smiles>Cc1cc(-c2nnc(N)nc2-c2ccccc2)cc(C)n1</smiles>

Adenosine $A_{2 A}$ antagonist<smiles>[R]c1ccc(-c2nc(SCC(=O)OCC)nnc2-c2ccc(OC)cc2)cc1</smiles>

Neuroprotective \& Genoprotective

Figure 8: Triazine containing drugs as selective COX-2 inhibitor, adenosine A2A antagonist and neuro/genoprotectives. 
Fused nitrogen rich heterocycles are of special interest among medicinal chemists. Some imidazo-1,3,5-triazine derivatives were explored to have focal adhesion kinase (FAK) inhibition potential with antiangiogenic and anticancer activity (Figure 9). The best inhibitor in this series had IC50 value of $50 \mathrm{nM}$ against FAK enzymatic activity [13].

Some imidazo-1,2,4-triazine derivatives were described and evaluated as potent, selective and orally bioavailable dual insulin-like growth factor receptor-1 (IGF-1R) and insulin receptor (IR) inhibitors (Figure 9). These receptors are transmembrane tyrosine kinases which their activation results in tumor genesis. A molecular modeling study has revealed that the imidazotriazine ring has multiple hydrogen bonding interactions mimicking the adenine moiety of ATP in the ATP-binding site of the enzyme [14].<smiles>Nc1ncnn2c(C3CCC3)nc(-c3ccc4ccc(-c5ccccc5)nc4c3)c12</smiles>

Dual inhibitor of IGF-1R and IR<smiles>C=CCOC(=O)NCc1ccc(Nc2nc(Nc3ccccc3C(=O)NC)n3ccnc3n2)cc1</smiles>

FAK inhibitor

Figure 9: Imidazotriazine containing drugs as novel anticancer agents.

Interestingly, triazole-1,2,4-triazines are widely used in the design and development of c-Met tyrosine kinase inhibitors. In the last years, some triazole-1,2,4-triazines have been synthesized and evaluated as potent and selective c-Met kinase inhibitors (Figure 10). Presence of this fused heterocyclic core infers high potency and selectivity to the compounds because this core is able to form some key interactions as hydrogen bonds with Asp1222 and Tyr1230 at the active site which is very crucial in the selectivity of c-Met inhibition towards various kinase receptors $[15,16]$.<smiles>[R]c1ccc(-c2cnc3nnc(COc4ccnc5cc([R])ccc45)n3n2)cc1</smiles>

c-Met kinase inhibitor<smiles>FC(F)(c1ccc2ncccc2c1)c1nnc2ncc([Al])nn12</smiles>

c-Met kinase inhibitor

Figure 10: Triazolotriazine containing drugs as potent and selective c-Met kinase inhibitors. 


\section{Medicinal \& Analytical Chemistry International Journal}

\section{Conclusion}

Nitrogen rich heterocycles are attractive cores or fragments and potentially are able to form energetic and diverse chemical bonds at the binding site of biological drug targets. According to the literature, presence of this type of heterocycles infers high potency, selectivity and favorite pharmacokinetic profile to the parent drug. Nitrogen rich heterocycles are widely using in the future trends of medicinal chemistry.

\section{References}

1. Ray PC, Kiczun M, Huggett M, Lim A, Prati F, et al. (2017) Fragment library design, synthesis and expansion: nurturing a synthesis and training platform. Drug Discov Today 22(1): 43-56.

2. Abdellatif KRA, Fadaly WAA, Kamel GM, Elshaier YAMM, El-Magd MA (2018) Design, synthesis, modeling studies and biological evaluation of thiazolidine derivatives containing pyrazole core as potential anti-diabetic PPAR-gamma agonists and anti-inflammatory COX-2 selective inhibitors. Bioorg Chem 82: 86-99.

3. Taban IM, Elshihawy H, Torun B, Zucchini B, Williamson CJ, et al. (2017) Novel Aryl Substituted Pyrazoles as Small Molecule Inhibitors of Cytochrome P450 CYP121A1: Synthesis and Antimycobacterial Evaluation. J Med Chem 60(24): 10257-10267.

4. Li M, Dong Y, Yu X, Li Y, Zou Y, et al. (2017) Synthesis and Evaluation of Diphenyl Conjugated Imidazole Derivatives as Potential Glutaminyl Cyclase Inhibitors for Treatment of Alzheimer's Disease. J Med Chem 60(15): 6664-6677.

5. Mortensen DS, Perrin-Ninkovic SM, Shevlin G, Elsner J, Zhao J, et al. (2015) Optimization of a Series of Triazole Containing Mammalian Target of Rapamycin (mTOR) Kinase Inhibitors and the Discovery of CC115. J Med Chem 58(14): 5599-5608.

6. Hashemi SM, Badali H, Faramarzi MA, Samadi N, Afsarian MH, et al. (2015) Novel triazole alcohol antifungals derived from fluconazole: design, synthesis, and biological activity. Mol Divers 19(1): 15-27.

7. Hashemi SM, Badali H, Irannejad H, Shokrzadeh M, Emami S (2015) Synthesis and biological evaluation of fluconazole analogs with triazole-modified scaffold as potent antifungal agents. Bioorg Med Chem 23(7): 1481-1491.
8. Subramanian V, Knight JS, Parelkar S, Anguish L, Coonrod SA, et al. (2015) Design, synthesis, and biological evaluation of tetrazole analogs of $\mathrm{Cl}$ amidine as protein arginine deiminase inhibitors. J Med Chem 58(3): 1337-1344.

9. Congreve $\mathrm{M}$, Andrews SP, Dore AS, Hollenstein $\mathrm{K}$, Hurrell E, et al. (2012) Discovery of 1,2,4-Triazine Derivatives as Adenosine A(2A) Antagonists using Structure Based Drug Design. J Med Chem 55(5): 1898-1903.

10. Irannejad H, Kebriaieezadeh A, Zarghi A, MontazerSadegh F, Shafiee A, et al. (2014) Synthesis, docking simulation, biological evaluations and 3D-QSAR study of 5-Aryl-6-(4-methylsulfonyl)-3-(metylthio)-1,2,4triazine as selective cyclooxygenase-2 inhibitors. Bioorg Med Chem 22(2): 865-873.

11. Tuylu Kucukkilinc T, Safari Yanghagh K, Ayazgok B, Roknipour MA, Moghadam FH, et al. (2017) Synthesis and neuroprotective activity of novel 1,2,4-triazine derivatives with ethyl acetate moiety against $\mathrm{H}_{2} \mathrm{O}_{2}$ and $A \beta$-induced neurotoxicity. Medicinal Chemistry Research 26(11): 3057-3071.

12. Naderi N, Ghasemi Najarkolaee SM, Modanlookordi M, Shokrzadeh M, Irannejad H (2019) Genoprotective Effect of New Triazine Derivatives in Endosulfan Mediated Toxicity, an in vivo and in vitro Study. Letters in Drug Design \& Discovery 16(1): 52-57.

13. Dao P, Smith N, Tomkiewicz-Raulet C, Yen-Pon E, Camacho-Artacho M, et al. (2015) Design, synthesis, and evaluation of novel imidazo[1,2-a][1,3,5] triazines and their derivatives as focal adhesion kinase inhibitors with antitumor activity. J Med Chem 58(1): 237-251.

14. Jin M, Gokhale PC, Cooke A, Foreman K, Buck E, et al. (2010) Discovery of an Orally Efficacious Imidazo[5,1-f][1,2,4] triazine Dual Inhibitor of IGF-1R and IR. ACS Med Chem Lett 1(9): 510-515.

15. Chen F, Wang Y, Ai J, Zhan Z, Lv Y, et al. (2012) 0linked triazolotriazines: potent and selective c-Met inhibitors. Chem Med Chem 7(7): 1276-1285.

16. Zhan Z, Peng X, Liu Q, Chen F, Ji Y, et al. (2016) Discovery of 6-(difluoro(6-(4-fluorophenyl)$[1,2,4]$ triazolo[4,3-b][1,2,4]triazin-3yl)methyl)quinoline as a highly potent and selective c-Met inhibitor. Eur J Med Chem 116: 239-251. 